Trinity University

Digital Commons @ Trinity

Psychology Faculty Research

Psychology Department

9-2017

\title{
Food Insecurity and Eating Disorder Pathology
}

Carolyn Becker

Trinity University, cbecker@trinity.edu

Keesha M. Middlemass

Trinity University, kmiddlem@trinity.edu

Brigitte Taylor

Trinity University, btaylor1@trinity.edu

Clara Johnson

Trinity University, cjohnso9@trinity.edu

Francesca Gomez

Trinity University, fgomez@trinity.edu

Follow this and additional works at: https://digitalcommons.trinity.edu/psych_faculty

Part of the Psychology Commons

Publication Details

International Journal of Eating Disorders

\section{Repository Citation}

Becker, C. B., Middlemass, K., Taylor, B., Johnson, C., \& Gomez, F. (2017). Food insecurity and eating disorder pathology. International Journal of Eating Disorders, 509, 1031-1040. doi: 10.1002/eat.22735

This Post-Print is brought to you for free and open access by the Psychology Department at Digital Commons @ Trinity. It has been accepted for inclusion in Psychology Faculty Research by an authorized administrator of Digital Commons@ Trinity. For more information, please contact jcostanz@trinity.edu. 
Food Insecurity and Eating Disorder Pathology

Carolyn Black Becker, Ph.D. ${ }^{\text {a }}$, Keesha Middlemass, Ph.D. ${ }^{\text {b }}$ Brigitte Taylor ${ }^{\text {a }}$, Clara Johnson, B.A. ${ }^{a}$, and Francesca Gomez ${ }^{\text {a }}$

Trinity University

San Antonio, Texas

a. Department of Psychology

b. Department of Political Science

Contact: Carolyn Becker, Department of Psychology, Trinity University, One Trinity Place, San Antonio, TX 78212-7200; cbecker@trinity.edu

International Journal of Eating Disorders

Please do not distribute without permission of the authors.

Keywords: food insecurity, eating disorders, marginalized populations, binge eating, ethnicity 


\begin{abstract}
Objective: The primary aim of this study was to investigate eating disorder (ED) pathology in those living with food insecurity. A secondary aim was to investigate whether any-reason dietary restraint, weight self-stigma and worry increased as level of food insecurity increased. Method: Participants $(\mathrm{N}=503)$ seeking food from food pantries completed questionnaires assessing level of food insecurity, demographics, ED pathology, dietary restraint, weight selfstigma and worry.

Results: Consistent with hypotheses, participants with the highest level of food insecurity (i.e., adults who reported having hungry children in their household) also endorsed significantly higher levels of binge eating, overall ED pathology, any-reason dietary restraint, weight selfstigma and worry compared to participants with lower levels of food insecurity. Contrary to hypotheses, compensatory behaviors also increased as level of food insecurity worsened. Overall, $17 \%$ of those in the child hunger food insecurity group reported clinically significant ED pathology.
\end{abstract}

Discussion: This is the first study to assess the full spectrum of ED pathology in a low income, marginalized population with food insecurity. Given that food insecurity is a global concern, results from this study suggest that greater attention to the association between ED pathology and food insecurity is warranted by researchers around the world. 
Food Insecurity and Eating Disorder Pathology

Food security (FS) is most commonly defined as "all people at all times having physical, social and economic access to sufficient, safe, and nutritious food to meet dietary needs and food preferences for an active and healthy life" (Lang \& Barling, 2012; United Nations Food and Agriculture Organization, 2009). Food insecurity (FI) correspondingly is defined as inadequate access to sufficient food, both in terms of quantity and quality, secondary to lack of financial and other resources (Coleman-Jensen, Rabbitt, Gregory \& Singh, 2015). FI is a global problem, one that not only affects developing countries, but also some of the wealthiest countries in the world. For instance, in 2015, the United States Department of Agriculture (USDA) estimated that 15.8 million households in the United States (US) qualified as FI (Coleman-Jensen et al., 2015). These households represent almost 49 million individuals and 29 million adults. Children are significantly affected by FI; however, in approximately half of the US FI households with children only adults are FI (Coleman-Jensen et al., 2015). This is likely due to caregivers prioritizing food allocation to children and school meal programs (McIntyre, Glanville, Raine, Dayle, Anderson \& Battaglia, 2003).

A limited literature has documented an association between FI and some forms of psychopathology such as: depression/dysthymia, anxiety disorders and/or more broadly defined mental illness (Alaimo, Olson \& Frongillo, 2002; Davidson \& Kaplan, 2015; Muldoon, Kuff, Fielden \& Anema, 2013; Palar et al., 2015, Sorsdahl, Slopen, Siefert, Seedat, Stein \& Williams, 2010). To our knowledge, however, only one study investigated the association between eating disorders (EDs) and FI. This study investigated a range of eating behaviors (e.g., family meal frequency, sugar-sweetened beverage consumption) in both FS and FI parents of adolescents enrolled in Project EAT (Bruening, MacLehose, Loth, Story \& Neumark-Sztainer, 2012). A 
single question addressed binge eating. Results indicated that FI parents were more likely to endorse binge eating as compared to FS parents.

Despite the dearth of research investigating EDs in those with FI, there are good reasons to expect increased rates of EDs in this population, particularly those with the highest levels of FI who may experience significant food deprivation. For instance, research by Keys and colleagues documented the emergence of ED pathology in the male participants of the Minnesota Starvation Study (Keys et al., 1950; Tucker, 2006). Importantly, participants were screened for both physical and mental health concerns with the aim of recruiting as healthy a sample as possible. After establishing a mean baseline diet of approximately 3200 calories, intake was reduced to 1570 calories, or lower if needed, to induce weight loss for six months; participants then engaged in an experimental refeeding period. Both diagnostic symptoms of EDs (e.g., binge eating, sense of loss of control over eating), as well as commonly observed associated behaviors (e.g., excessive gum chewing, preoccupation with food, stealing food, eating very slowly), emerged during the starvation and refeeding phases, as well as post-study (Kalm \& Semba, 2005; Tucker, 2006).

In addition, those with FI who live in urban environments often live in food deserts and food swamps. In the US, food deserts are defined as census tracts in which the population is both low income and lacks access to affordable/nutritious food (Dutko, 2012; Kato \& Irvin, 2013). Food swamps are urban areas dominated by inexpensive food retailers (e.g., fast food retailers) selling highly palatable food (HPF: i.e., highly processed foods high in sugar, salt and fat) as opposed to healthy and nutrient-dense foods (Kato \& Irvin, 2013). Animal model research by Boggiano and colleagues (2007) strongly implicates HPF consumption in binge eating. More specifically, Boggiano et al. found that merely introducing HPF into the diets of rats will lead some rats to 
binge eat, though they did not binge eat while on a diet of rat chow. Also, when stressed, binge eating-prone rats decrease consumption of rat chow but not HPF. Given that urban individuals who are FI often are stressed secondary to living in poverty, it seems reasonable to hypothesize that living in a combined food desert/food swamp dominated by HPF may increase binge eating.

The primary aim of this study was to assess ED pathology in an urban adult sample with FI. FI exists on a continuum, with some FI adults experiencing only moderate disruptions in food availability whereas others experience extreme hunger secondary to restricting their own intake to feed hungry children. We hypothesized that higher levels of FI would be associated with increased ED pathology, driven largely by increases in binge eating and overeating. The Keys et al. (1950) study suggests that extreme dietary restriction may increase rates of ED pathology in humans generally; thus, we hypothesized that the association between ED pathology and FI would emerge regardless of gender or ethnicity. We also hypothesized that we would not see corresponding increases in compensatory behaviors.

A secondary aim was to investigate dietary restraint for any reason, internalized weight stigma, and anxiety in those with FI. We hypothesized that we would see increased rates of selfreported dietary restriction in those with the highest level of FI provided we assessed dietary restriction for any reason as opposed to simply for weight and shape concerns. We assessed anyreason dietary restriction because FI adults have more reasons to restrict than food secure adults (e.g., to stretch food supplies, to reserve food for children). Results from Keys et al. (1950) suggest that ED pathology may be associated with dietary restraint that occurs for reasons other than weight and shape concerns.

FI has been found to be associated with obesity (Franklin, Jones, Love, Puckett, Macklin \& White-Means, 2012). As such, FI adults may receive weight stigmatizing messages from both 
public health anti-obesity campaigns as well as medical providers, both of which could encourage restriction. Anti-obesity campaigns are common in San Antonio, where this study was conducted; in 2010, San Antonio was awarded 15.6 million dollars to fight obesity (Belasco, 2015). Thus, we also investigated internalized weight stigma to determine if those with FI are internalizing cultural negative attitudes about increased weight. We hypothesized that internalized weight stigma would increase as FI increased. Finally, those with FI live with a considerable amount of stress. Thus, we also investigated anxiety with a focus on worry. We again hypothesized that this would increase as the level of FI increased.

\section{Method}

\section{$\underline{\text { Participants }}$}

The sample consisted of 503 adult clients of food pantries affiliated with the San Antonio Food Bank (SAFB) who completed measures in exchange for a $\$ 5$ gift card to a local grocery chain. Table 1 presents demographics, including participants' age, gender, highest level of education, ethnicity, and current household income. Almost $65 \%$ of the sample identified as Latino/Hispanic; this is consistent with the overall demographics of the city (https://censusreporter.org/profiles/16000US4865000-san-antonio-tx/).

\section{$\underline{\text { Procedure }}$}

This study received Institutional Review Board (IRB) approval and was run in collaboration with SAFB. SAFB serves FI households via 530 partner agencies (e.g., soup kitchens, food pantries) throughout Southwest Texas. After SAFB approved the study, staff provided locations and operating times for partner agencies. Research assistants (RAs) contacted individual agencies to orient staff to the study and sent copies of documents as requested (i.e., questionnaire, IRB approval). Once a partner agency agreed to participate, staff provided insight 
regarding best practices for recruiting participants depending on the food distribution set-up. As such, procedure varied somewhat based on agency. Typically, staff members introduced RAs to groups of clients who were waiting to collect food. RAs then approached clients in a manner designed to not disrupt food distribution procedures. For instance, if clients were waiting in a line, RAs started with clients who needed to wait at least 20 minutes based on line position so that they would have adequate time to finish the questionnaire. Some mobile pantries distributed food directly into clients' cars; RAs then approached cars one by one. In other cases, pantries located RAs at a table and clients approached the table to learn more about the study.

Using a standardized recruitment script, RAs asked clients if they were interested in answering some questions while they waited. For those who showed interest, RAs provided standardized basic information. All materials and scripts were available in either English or Spanish. If participants remained interested, RAs then reviewed each component of the consent form using another script, and gave participants time to read the consent form and provide written consent. Participants completed questionnaires with RAs nearby to answer questions. If participants had difficulty reading, RAs read questions aloud to participants and helped them indicate their answers. After completion, RAs debriefed participants and recorded any participant feedback for future reference. All participants also received a list of free/low-cost local mental health resources.

\section{$\underline{\text { Measures }}$}

In addition to collecting demographic information in Table 1, participants completed the Radimer Cornell Food Insecurity Measure (RCFIM: Kendell, Olson \& Fongillo, 1995; Radimer, Olson \& Campbell, 1992). The RCFIM assesses the Radimer continuum of FI, which progresses from household food anxiety/uncertainty to child hunger, in which children in the household do 
not have enough to eat. Sample questions include: "The food that I bought didn't last and I didn't have money to buy more," and “I know my child(ren) are hungry sometimes, but I can't afford more food." Items are rated on a Likert scale $(0=$ Not True $; 1=$ Sometimes True $; 2=$ Always True). Participants are rated as: not FI (i.e., did not meet criteria for FI); household FI (i.e., participants report anxiety about food, eating the same thing repeatedly because of lack of resources, and food running out); individual FI (i.e., participants report being hungry at times because they lack food); and child hunger FI (i.e., participants report inability to feed their children secondary to lack of resources). It is important to highlight that the child hunger group consists of adults who report having hungry children in their household; the presumption is that hungry children indicate even hungrier adults given the propensity of most caregivers to prioritize feeding children. Questions on the RCFIM are divided into three clusters designed to measure the three conceptual categories along the FI continuum. Participants who score greater than zero on questions in the lowest severity cluster (e.g., eating the same thing repeatedly because of lack of resources) but at zero on all questions in the higher severity cluster (e.g., reporting being hungry secondary to food scarcity) are designated FI at the household level. Those who score greater than zero on any higher severity questions but at zero for child hunger questions (e.g., reporting children are hungry) are designated FI at the individual level. If participants score greater than zero on any of the questions concerning child hunger, participants are categorized as child hunger FI. Research supports the internal consistency and the construct and criterion-related validity of the RCFIM (Kendell et al., 1995). We found excellent internal consistency within our sample (Cronbach's $\alpha=.941)$.

We used 18 items from the Eating Disorder Diagnostic Scale for DSM 5 (EDDS-5) to assess ED pathology (Stice, Fisher \& Martinez, 2004). The EDDS is a brief self-report measure 
designed to assess the spectrum of EDs. We omitted questions about weight and height because very low income individuals often lack regular access to physicians and scales, which are a luxury item. Thus, information collected was unlikely to be reliable. Research with the original EDDS supports the criterion validity with interview-based diagnoses, internal consistency, and convergent validity with ED risk factors, as well as sensitivity to change and predictive validity (Stice, Fisher \& Martinez, 2004). We selected the EDDS-5 over the EDDS-4 for two reasons. First, KM, who has extensive experience working in low-income marginalized populations, said the EDDS-5 was somewhat easier to understand. Second, the EDDS-5 assesses night eating, which we hypothesized would be an issue in this population. Because the night eating question was very complicated, yet of great interest, we split this item into two questions to facilitate comprehension. To score EDDS items, per Stice et al. (2004) and Krabbenborg et al. (2012), we computed a standardized summed composite score. In the present sample, the EDDS items showed excellent internal consistency $(\alpha=.911)$.

For dietary restraint, we used three items from dietary restraint subscale of the Eating Disorder Examination Questionnaire (EDE-Q) (Fairburn, 2008), including restraint over eating, avoidance of eating, and food avoidance. EDE-Q items use a 7-point Likert scale $(0=$ No Days to $6=$ Every Day) rated over the past 28 days. The three items showed acceptable internal consistency $(\alpha=.741)$. As noted above, we eliminated the caveat that dietary restraint was for weight and shape concerns.

The Weight Self-Stigma Questionnaire (WSSQ) measures the internalization of weight bias on two levels, self-devaluation and fear of enacted stigma (Lillis, Luoma, Levin \& Hayes, 2010); scores from the two scales are summed for a total score. Research supports the reliability and validity of the WSSQ (Lillis et al., 2010). Items are rated on a 7-point Likert scale (1 = Strongly 
Disagree to $7=$ Strongly Agree). Participants rated their level of agreement with 12 explicit weight bias statements such as "I became fat because I'm a weak person" and "People think that I am to blame for being fat." We cut two items from the enacted sub-scale secondary to question complexity. The internal consistency of the 10-items was excellent $(\alpha=.956)$.

To assess anxiety/worry, we used eight items from the well-validated Penn State Worry Questionnaire (PSWQ) (Myer et al., 1990). Items were excluded if they were a) deemed to be too complicated by KM or b) reverse scored, which also raised concerns about comprehension. Sample items used include: "My worries overwhelm me," "Many situations make me worry," and "When I am under pressure I worry a lot." Items are rated on a 5-point Likert scale (1 = Not at All Typical of Me to 5 = Very Typical of Me). The PSWQ items used in this study had excellent internal consistency in our sample $(\alpha=.952)$.

Those with FI often have lower levels of education; thus, we reviewed all items using online software and adjusted them, as necessary, to a 6th grade reading level. As we had already removed more complicated questions, many questions were unchanged. Because of the high prevalence of Spanish speakers in San Antonio, we translated measures into Spanish and then had an independent bilingual consultant back translate to ensure the meaning of each question remained the equivalent in English and Spanish. The Spanish version was then reviewed by a bilingual person who grew up in San Antonio; this person made a few minor adjustments to reflect Spanish dialect commonly spoken in San Antonio.

Prior to starting the main study, we obtained IRB approval to survey 32 university staff (secretarial, dining, grounds keeping and custodial) to assess the clarity of and the time needed to complete the measures. We recorded feedback and used this information to make final adjustments. Sample changes included lowering the lowest level of the education to "no grade 
school" so as to not alienate participants. Additionally, a few participants with lower levels of education found the consent form to be overwhelming; therefore, changes were made to the consent form and process.

\section{Data Analysis}

For the main analyses, we conducted six planned one-way ANOVAs to test hypotheses regarding the degree to which ED pathology, weight self-stigma, any-reason dietary restraint, and worry worsened as FI increased. Given that this is the first study to investigate these variables in those with FI and because these analyses tested clear hypotheses, we did not adjust for multiple tests. We only conducted post-hoc tests in the case of a significant omnibus test.

Because those with FI are a significantly marginalized population and this is the first study to investigate ED pathology in this population, we also provided descriptive data (i.e., frequencies) for a) those clearing the clinically significant cutoff for ED pathology and b) specific ED behaviors. Frequencies are easier to understand than means and are important for a) demonstrating the degree to which pathological behavior is normative enough to be viewed as a possible public health problem (Fiske, Fallon, Blissmer \& Redding, 2014) and b) communicating with stakeholders in the community, such as policy makers and non-profit agencies (Becker, 2017). We also used the frequencies to explore whether or not increases in mean EDDS scores were largely driven by binge eating alone (as hypothesized) or included compensatory behaviors (contrary to our hypotheses), and to investigate if there were marked gender or ethnicity differences in overall ED pathology. With the exception of the frequencies for clinically significant ED pathology, we did not conduct statistical analyses on the frequency data secondary to concerns about multiple tests.

\section{Results}




\section{$\underline{\text { Main Analyses }}$}

Based on the RCFIM, we divided the sample into four groups: not FI ( $n=41)$, household FI $(n=45)$, individual FI $(n=190)$ and child hunger FI $(n=227)$; child hunger represents the most severe level of FI. See Table 1 for demographics by FI group. We labeled the first group as not FI, instead of food secure, because these individuals sought food from food pantries, indicating behaviorally that they likely are not completely food secure. Notably, a slightly smaller percentage of this group (46.3\%) reported earning less than $\$ 10,000$ per year compared to the remaining groups $(51.1 \%-62.6 \%)$, which may mean that this group lives on the edge of FI. Because this group was slightly older, this group also may experience somewhat greater income protection via social security. The only other major demographic differences included a greater percentage of males (36.6\% versus 17.8\%-25.8\%) and Black/African American individuals $(29.3 \%$ versus $14.7 \%-17.8 \%)$ in the not FI group.

Consistent with our hypotheses, ED pathology significantly differed between groups, $F(3$, $427)=10.49, p=.0001, \eta^{2}=.069$. Post-hoc tests indicated that the child hunger group reported elevated ED pathology compared to other groups (see Table 2 for means and standard deviations). Weight stigma also significantly differed for fear-of-enacted stigma, $F(3,465)=$ $5.40, p=.001, \eta^{2}=.034$, self-devaluation stigma, $F(3,460)=4.29, p=.005, \eta^{2}=.027$; and total stigma, $F(3,451)=4.71, p=.003, \eta^{2}=.030$. Post-hoc analyses indicated that across all three indices, the child hunger FI group reported significantly increased weight stigma compared to the not FI and individual FI groups. Mean scores for household FI fell between those for the not FI and individual FI groups, but the difference from the child hunger group did not reach significance $(\mathrm{p}=.060)$; this may have occurred because the household FI scores were higher than the not FI group and the $n$ for this group was markedly lower than the individual FI group, thus 
reducing statistical power. For any-reason dietary restraint, groups again differed significantly, $F(3,462)=19.17, p=.0001, \eta^{2}=.111$. Post-hoc tests indicated that the child hunger group reported elevated dietary restraint relative to the other groups. Also, those in the individual FI group reported elevated dietary restraint compared to the household group. Finally, the groups differed on worry, $F(3,428)=33.18, p=.0001, \eta^{2}=.233$. Post-hoc tests indicated that the child hunger group reported higher levels of worry relative to the other groups. The individual FI group also reported significantly increased worry relative to the household FI and not FI groups. Frequency of Clinically Significant ED Pathology

Krabbenborg et al. (2012) found that a cutoff of 16.5 on the EDDS composite score optimally distinguished clinically significant EDs. Table 3 lists the percentage of each group above the EDDS cutoff for the total sample and by gender and ethnicity. We separated findings by gender and ethnicity because of the unique nature of this sample, and because we hypothesized that we would not see major differences in ED pathology in those with the highest levels of FI based on gender or ethnicity. Because of the small cell size for White ethnicity in the not FI and household FI groups, White was included in the "other" category. Consistent with our hypotheses, for the total sample, the percentage of those scoring above 16.5 increased in a linear manner as FI increased, with $17 \%$ of those in the child hunger group clearing the clinical cutoff. Also consistent with our hypotheses, rates of those scoring above the cutoff remained fairly consistent across both gender and ethnicity in the child hunger group $\left(14.8 \%-20 \%\right.$; gender $\chi^{2}(1$, $N=428)=1.39, p=.238$; ethnicity $\left.\chi^{2}(2, N=426)=1.20, p=.550\right)$. This indicates that the highest level of FI was associated with elevated rates of clinical ED pathology regardless of gender or ethnicity.

Because we split one EDDS question into two questions to facilitate comprehension, it was 
conceivably easier to score above the clinical cutoff because an extra score contributed to the total. Thus, we reviewed every "clinical" case to see if the additional question/score edged anyone just above the cutoff. In no case did this happen. All cases scoring above the cutoff did so by a larger margin than the highest score on the split question. We also compared the difference in mean scores between the clinical and non-clinical groups in Krabbenborg et al. (2012) and the present study. In Krabbenborg et al., the difference in mean EDDS scores was 28.29. In this study, the difference was 29.30. Finally, we compared percentages of objective overeating/ objective and subjective binge episodes; night eating (i.e., consumption of a large amount of food after waking from sleep with distress); vomiting; and laxative/diuretic use in those scoring above and below the cutoff, as well as the percentage scoring four or higher on weight/shape concerns. In those below the cutoff, $23.2 \%$ reported binge eating/overeating, $22.1 \%$ reported night eating, $11.3 \%$ reported vomiting, $15.2 \%$ reported use of laxatives/diuretics, and $24.5 \%$ scored above four on weight/shape concerns. In contrast, above the cutoff, $94 \%$ reported overeating/binge eating, $84.3 \%$ reported night eating, 50\% reported vomiting, $56.9 \%$ reported use of laxatives/diuretics, and 70.6\% scored above four on weight/shape concerns. Taken together, these findings support the use of the Krabbenborg et al. (2012) cutoff in this sample.

\section{Frequencies of ED Behaviors}

Table 3 displays frequencies of key ED behaviors, including objective and subjective binge eating, objective overeating, night eating, vomiting, laxative/diuretic use, skipping two meals in a row, and exercising harder than usual because of overeating. All compensatory behaviors were ostensibly to "prevent weight gain or counteract the effects of eating" per the EDDS. It is important to note that because of the structure of the EDDS, participants could only be classified as endorsing objective binge eating, objective overeating or subjective binge eating. Thus, if a 
participant met criteria for objective binge eating (i.e., eating a large amount of food with loss of control), they were classified as only having objective binge eating. However, it is possible that the same participant also engaged in subjective binge eating and/or objective overeating. Thus, objective overeating and subjective binge eating frequencies likely represent an underestimate.

As hypothesized, the child hunger group reported the highest levels of objective binge eating, objective overeating, subjective binge eating, and night eating. Contrary to our hypotheses, we found a similar trend for compensatory behaviors including vomiting, laxative/diuretic use, skipping meals, and exercise. One EDDS question assesses shape/weight concerns in language that is similar to the Eating Disorder Examination (Fairburn, 2008); both measures use a 0-6 point measure that are scaled similarly. Table 3 includes the percentage of participants who endorsed $\geq 4$ on importance of shape/weight; a score of four is used on the EDE as meeting a clinical level. Consistent with other findings, this percentage was most elevated in the child hunger group.

\section{Discussion}

To our knowledge, this study represents the first investigation of the association between FI and ED pathology. Results supported our hypotheses that increased levels of FI would be associated with increased levels of ED pathology, with the mean EDDS score for the child hunger group being significantly higher than the other three groups. Also, $17 \%$ of the child hunger group reported sufficient ED behavior to clear the Krabbenborg et al. (2012) clinical cutoff for the EDDS in comparison to less than $3 \%$ for the lowest two FI levels and approximately $9 \%$ in the individual level. Importantly, we did not observe marked gender or ethnicity differences in rates of clinical significantly EDs in the child hunger group, which supports the supposition that severe FI may be an ED risk factor across demographic groups. 
This hypothesis is supported by Keys et al. (1950) who reported the emergence of ED pathology secondary to dietary restriction not induced by weight/shape concerns. However, longitudinal research is needed to determine if severe FI is, in fact, a prospective risk factor for EDs. Importantly, the lack of ethnicity differences is also supported by a recent study in a large $(\mathrm{N}=$ 9713) sample of university students (Lipson \& Sonneville, 2017).

Also consistent with our hypotheses, any-reason dietary restraint, objective and subjective binge eating, objective overeating, and night eating all were elevated among the child hunger group. Contrary to our hypotheses, compensatory behaviors also increased in a similar fashion. This was unexpected. Since starting this research, however, we have received anecdotal reports of binging and vomiting in those who were formerly FI. Further, reports from Keys et al. (1950; Tucker, 2006) reveals that some participants post-study engaged in such large episodes of binge eating that they vomited. As such, it is possible that extreme dietary restriction in the child hungry group leads to significant binge eating, which in turn leads to compensatory behaviors to reduced discomfort from binge eating. Once compensatory behaviors start, they may take on other features such as affect regulation; further research, however, is needed to understand the nature of compensatory behaviors in this population.

Kazdin (2017) has highlighted a need for the mental health field to address the treatment gap, which refers to the discrepancy between the number of people who could use mental health services and the number who actually receive them. Kazdin further notes that the dominant mode by which psychosocial interventions are provided (one-on-one by an expert clinician) will never be sufficiently scalable to reduce the burden of mental illness, even in resource rich countries. Results from the present study indicate that the ED field should seriously consider Kazdin's call to develop alternative intervention models. Further research is clearly necessary to both replicate 
the results of this study and elucidate etiological pathways that may be unique to this population; such research will be critical to guide the development of new treatment models and prevention interventions. However, it is important to realize that with the exception of guided self-help for bulimia nervosa and binge eating disorder, most psychosocial interventions within the ED field rely heavily on expert therapists and have limited potential for low-cost scalability. Research by Patel et al. (2010) suggests that some behavioral interventions can be simplified and task-shifted to community lay providers so as to reach low income populations. This might be one path for moving forward to assist those with FI who have EDs.

As hypothesized, weight stigma (enacted, self-devaluation, total) also increased across groups with the highest level reported by the child hunger group. Because we did not assess weight status, we do not know how many participants were overweight/obese. However, FI is strongly associated with poverty, and both correlate with overweight/obesity status, although research suggests the relationship between FI and weight status is complicated (Franklin et al., 2012). Nonetheless, given obesity demographics for San Antonio and reports by SAFB that many clients are overweight or obese (Neira, 2017, personal communication), it is likely many in the sample were of higher weight status. Total weight self-stigma scores for the lowest levels of FI fell below the non-treatment seeking sample in Lillis et al. (2010), whereas total scores for the child hunger group fell between the non-treatment and treatment seeking samples. This is notable because this measure is scored as a total and we cut two items from the enacted subscale that we deemed too complicated, thus reducing total scores. In summary, results from this study raise the possibility that weight stigma is a significant problem for some with FI. As such, further research is warranted, particularly given that many anti-obesity campaigns target low-income, 
marginalized populations. Because we did not collect weight and height data, future research needs to explore the relationships between BMI, FI and weight stigma.

This study has several limitations. First, secondary to the typical education-level of this population, we altered several measures (i.e., adjusted wording, cut complicated items) to make them comprehensible. This is standard practice when studying low-education, marginalized populations; from a psychometric perspective, however, this is less than optimal. Second, although we back translated Spanish translations to ensure that the English and Spanish versions were equivalent, we did not conduct a validity study of the measures in Spanish. Fortunately, $79 \%$ of participants identified English as their first language and only a minority completed the questionnaire in Spanish. Third, we studied correlations and cannot presume causation. Thus, longitudinal and qualitative research is needed to replicate and better understand the trends identified here. Fourth, the sample was a convenience sample versus one designed to be representative. Fifth, we did not assess weight and height and could not look at the association of BMI with the other study variables, in particular weight stigma. This is a major limitation that should be addressed in follow-up research. One strength, however, is that we assessed the level of FI as opposed to assuming all individuals who seek food from a food pantry are equally FI, as is commonly done in many FI studies.

In conclusion, the present study suggests that higher levels of FI are associated with increased levels of ED pathology. To date, almost no research has investigated EDs in this population. Given that FI is a global problem that affects a wide range of individuals who live under different circumstances, we hope that this study fosters additional research investigating FI and EDs. 


\section{References}

Alaimo, K., Olson, C. M., \& Frongillo, E. A. (2002). Family food insufficiency, but not low family income, is positively associated with dysthymia and suicide symptoms in adolescents. The Journal of Nutrition, 132(4), 719-725.

Becker C.B. (2017). From efficacy to global impact: lessons learned about what-not-to-do in translating our research to reach. Behavior Therapy (advanced online publication http://dx.doi.org/10.1016/j.beth.2016.12.007).

Belasco, J. (2015, June 7). Health Department has long history of saving lives. San Antonio Express News. Retrieved from http://www.expressnews.com/150years/education health/article/Health-department-has-long-history-of-saving-and-6302048.php.

Boggiano, M. M., Artiga, A. I., Pritchett, C. E., Chandler-Laney, P. C., Smith, M. L., \& Eldridge, A. J. (2007). High intake of palatable food predicts binge-eating independent of susceptibility to obesity: an animal model of lean vs obese binge-eating and obesity with and without binge-eating. International Journal of Obesity, 31(9), 1357-1367. doi:10.1038/sj.ijo.0803614

Bruening, M., MacLehose, R., Loth, K., Story, M., \& Neumark-Sztainer, D. (2012). Feeding a family in a recession: food insecurity among Minnesota parents. American Journal of Public Health, 102(3), 520-526. doi:10.2105/AJPH.2011.300390

Coleman-Jensen, A., Rabbitt, M., Gregory, C., \& Singh, A. Household Food Security in the United States in 2015, ERR-215 (Washington, DC: US Department of Agriculture, Economic Research Service, September 2016). 
Davison, K. M., \& Kaplan, B. J. (2015). Food insecurity in adults with mood disorders: prevalence estimates and associations with nutritional and psychological health. Annals of General Psychiatry, 14(1), 21. doi:10.1186/s12991-015-0059-x

Dutko, P. (2012). Food deserts suffer persistent socioeconomic disadvantage. Choices: The Magazine of Food, Farm \& Resource Issues, 27(3), 1-4.

Fairburn, C. G. (2008). Cognitive behavior therapy and eating disorders. New York: Guilford Press.

FAO. (2009). The state of food insecurity in the world 2009. Meeting the 2015 International Hunger Targets: Taking Stock of Uneven Progress. Retrieved from ftp://ftp.fao.org/docrep/fao/012/i0876e/i0876e_flyer.pdf.

Fiske L., Fallon E. A., Blissmer B., \& Redding, C. A. (2014). Prevalence of body dissatisfaction among United States adults: review and recommendations for future research. Eating Behaviors 15(3): 357-365.

Franklin, B., Jones, A., Love, D., Puckett, S., Macklin, J., \& White-Means, S. (2012). Exploring mediators of food insecurity and obesity: a review of recent literature. Journal of Community Health, 37(1), 253-264. doi:10.1007/s10900-011-9420-4

Kalm, L. M., \& Semba, R. D. (2005). They starved so that others be better fed: remembering Ancel Keys and the Minnesota experiment. The Journal of Nutrition, 135(6), 1347-1352.

Kato, Y., \& Irving, C. (2013). Flow of food and people across the city: an examination of local food access in a New Orleans food desert. Spaces and Flows: An International Journal of Urban and Extra Urban Studies, 3(2), 45-56. doi:10.18848/2154-676/CGP/v03i02/53693 
Kazdin, A. E. (2017). Addressing the treatment gap: a key challenge for extending evidencebased psychosocial interventions. Behaviour Research and Therapy, 88, 7-18.

Kendall, A., Olson, C. M., \& Frongillo Jr, E. A. (1995). Validation of the Radimer/Cornell measures of hunger and food insecurity. The Journal of Nutrition, 125(11), 2793-2801.

Keys, A., Brozek, J., Henschel, A., Michelsen, O., Taylor, H. L., Simonson, E., ... \& Wells, S. (1950). The biology of human starvation. Volumes 1 and 2. The Biology of Human Starvation. Volumes 1 and 2.

Krabbenborg, M. A., Danner, U. N., Larsen, J. K., Veer, N., Elburg, A. A., Ridder, D. T., ... \& Engels, R. C. (2012). The eating disorder diagnostic scale: psychometric features within a clinical population and a cut-off point to differentiate clinical patients from healthy controls. European Eating Disorders Review, 20(4), 315-320. doi:10.1002/erv.1144

Lang, T., \& Barling, D. (2012). Food security and food sustainability: reformulating the debate. The Geographical Journal, 178(4), 313-326. doi:10.1111/j.1475-4959.2012.00480.x.

Lillis, J., Luoma, J. B., Levin, M. E., \& Hayes, S. C. (2010). Measuring weight self-stigma: the weight self-stigma questionnaire. Obesity, 18(5), 971-976. doi:10.1038/oby.2009.353

Lipson, S., \& Sonneville, K. (2017). Eating disorder symptoms among undergraduate and graduate students at 12 U.S. colleges and universities. Eating Behaviors, 24, 81-88. doi:10.1016/j.eatbeh.2016.12.003

Meyer, T. J., Miller, M. L., Metzger, R. L., \& Borkovec, T. D. (1990). Development and validation of the Penn State worry questionnaire. Behaviour Research and Therapy, 28(6), 487-495. doi:10.1016/0005-7967(90)90135-6 
McIntyre, L., Glanville, N. T., Raine, K. D., Dayle, J. B., Anderson, B., \& Battaglia, N. (2003). Do low-income lone mothers compromise their nutrition to feed their children? Canadian Medical Association Journal, 168(6), 686-691.

Muldoon, K. A., Duff, P. K., Fielden, S., \& Anema, A. (2013). Food insufficiency is associated with psychiatric morbidity in a nationally representative study of mental illness among food insecure Canadians. Social Psychiatry and Psychiatric Epidemiology, 48(5), 795803. doi:10.1007/s00127-012-0597-3

Palar, K., Kushel, M., Frongillo, E. A., Riley, E. D., Grede, N., Bangsberg, D., \& Weiser, S. D. (2015). Food insecurity is longitudinally associated with depressive symptoms among homeless and marginally-housed individuals living with HIV. AIDS and Behavior, 19(8), 1527-1534. doi:10.1007/s10461-014-0922-9

Patel, V., Weiss, H. A., Chowdhary, N., Nalk, S., Pednekar, S., Chatterjee, S.,...Kirkwood, B. R. (2010). Effectiveness of an intervention led by lay health counsellors for depressive and anxiety disorders in primary care in Goa, India (MANAS): a cluster randomized controlled trial. Lancet, 376, 2086-2095.

Radimer, K. L., Olson, C. M., Greene, J. C., Campbell, C. C., \& Habicht, J. P. (1992). Understanding hunger and developing indicators to assess it in women and children. Journal of Nutrition Education, 24(1), 36S-44S.

Sorsdahl, K., Slopen, N., Siefert, K., Seedat, S., Stein, D. J., \& Williams, D. R. (2010). Household food insufficiency and mental health in South Africa. Journal of Epidemiology and Community Health, (5), 426-431. doi:10.1136/jech.2009.091462 
Stice, E., Fisher, M., \& Martinez, E. (2004). Eating disorder diagnostic scale: additional evidence of reliability and validity. Psychological Assessment, 16(1), 60-71. doi:10.1037/10403590.16 .1 .60

Tucker, T. (2006). The great starvation experiment: the heroic men who starved so that millions could live. New York: Simon and Schuster.

U.S. Census Bureau (2015). American community survey 5-year estimates. Retrieved from Census Reporter Profile page for San Antonio, TX. https://censusreporter.org/profiles/16000 US4865000-san-antonio-tx/. 
Table 1

Participant demographics.

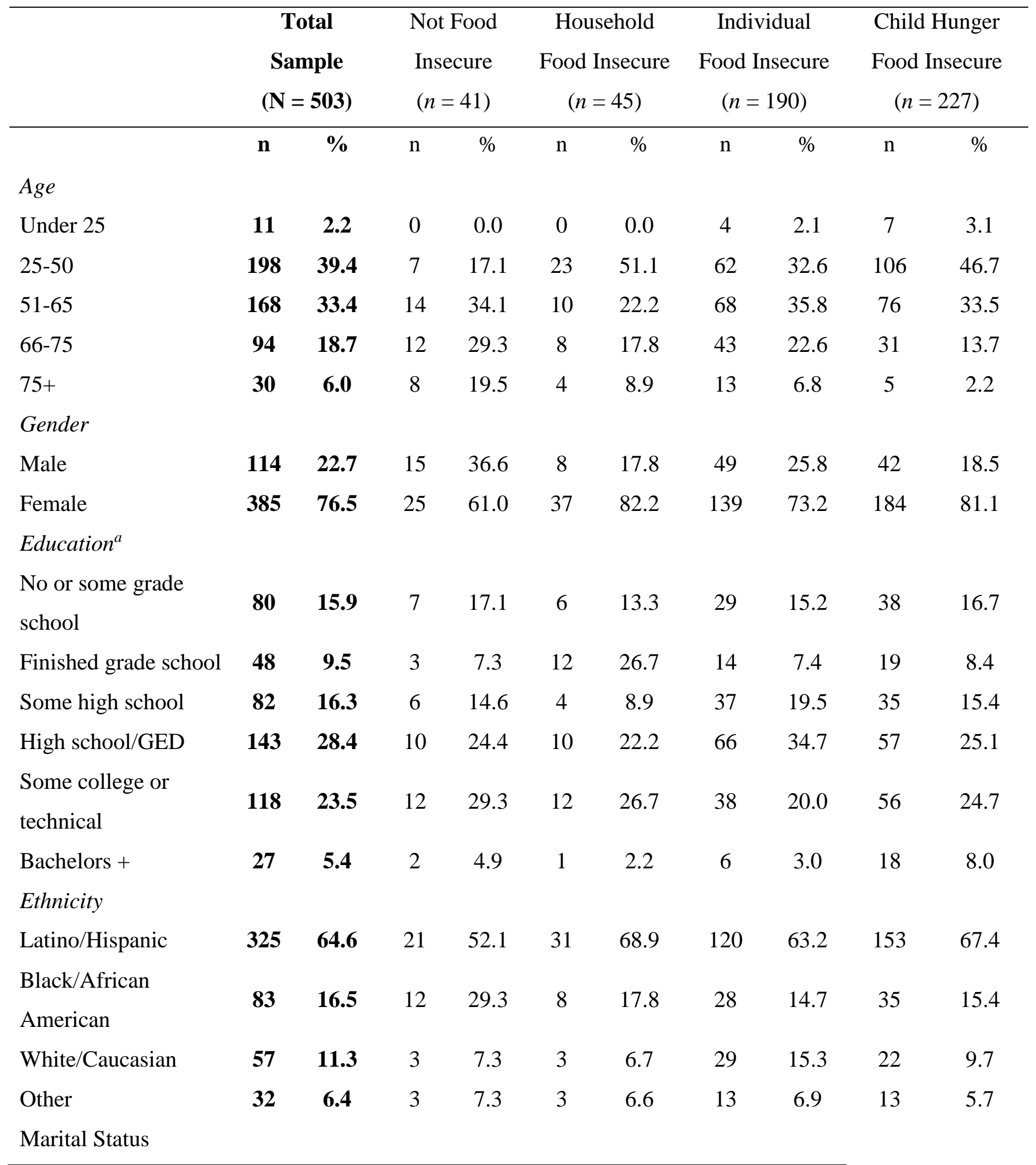




\begin{tabular}{lcccccccccc}
\hline Single & $\mathbf{1 6 0}$ & $\mathbf{3 1 . 8}$ & 11 & 26.8 & 12 & 26.7 & 59 & 31.1 & 78 & 34.4 \\
Married or living & $\mathbf{1 9 2}$ & $\mathbf{3 8 . 2}$ & 13 & 31.7 & 19 & 42.2 & 62 & 32.6 & 98 & 43.2 \\
with a partner & $\mathbf{2 6}$ & $\mathbf{5 . 2}$ & 2 & 4.9 & 4 & 8.9 & 10 & 5.3 & 10 & 4.4 \\
Separated & $\mathbf{6 5}$ & $\mathbf{1 2 . 9}$ & 6 & 14.6 & 6 & 13.3 & 33 & 17.4 & 20 & 8.8 \\
Divorced & $\mathbf{5 5}$ & $\mathbf{1 0 . 9}$ & 7 & 17.1 & 4 & 8.9 & 26 & 13.7 & 18 & 7.9 \\
Widowed & & & & & & & & & & \\
Current Annual & & & & & & & & & & \\
Household Income & & & & & & & & & & \\
$<$ \$10,000 & $\mathbf{2 9 7}$ & $\mathbf{5 9 . 0}$ & 19 & 46.3 & 23 & 51.1 & 119 & 62.6 & 136 & 59.9 \\
\$10,000-\$40,000 & $\mathbf{1 7 1}$ & $\mathbf{3 4 . 0}$ & 16 & 39.0 & 20 & 44.4 & 59 & 31.1 & 76 & 33.5 \\
\$40,000+ & $\mathbf{1 5}$ & $\mathbf{3 . 0}$ & 4 & 9.8 & 1 & 2.2 & 2 & 1.1 & 6 & 2.6 \\
\hline
\end{tabular}

${ }^{\text {a }}$ Education indicates highest level of education completed. 
Table 2

Means and Standard Deviations for Eating Disorder Pathology, Weight Stigma, Any Reason Dietary Restraint, and Anxiety

$\begin{array}{lcccc} & \text { Not Food } & \text { Household } & \text { Individual } & \text { Child Hunger } \\ & \text { Insecure } & \text { Food Insecure } & \text { Food Insecure } & \text { Food Insecure } \\ & M(S D) & M(S D) & M(S D) & M(S D) \\ \text { EDDS } & -5.19(8.77)^{\mathrm{a}} & -5.11(7.29)^{\mathrm{a}} & -.86(10.45)^{\mathrm{a}} & 3.40(13.40)^{\mathrm{b}} \\ \text { WSSQ enacted } & 7.77(7.15)^{\mathrm{a}} & 8.34(5.85)^{\mathrm{ab}} & 9.23(7.10)^{\mathrm{a}} & 11.43(7.61)^{\mathrm{b}} \\ \text { WSSQ self } & 12.46(11.22)^{\mathrm{a}} & 14.70(10.01)^{\mathrm{ab}} & 14.95(10.60)^{\mathrm{a}} & 17.86(10.79)^{\mathrm{b}} \\ \text { WSSQ total } & 20.23(17.97)^{\mathrm{a}} & 23.15(15.13)^{\mathrm{ab}} & 24.09(17.18)^{\mathrm{a}} & 29.18(18.03)^{\mathrm{b}} \\ \text { EDEQ-DR } & 1.59(1.32)^{\mathrm{ab}} & 1.36(.51)^{\mathrm{a}} & 2.02(1.27)^{\mathrm{b}} & 2.71(1.51)^{\mathrm{c}} \\ \text { PSWQ } & 13.94(6.85)^{\mathrm{a}} & 17.38(9.06)^{\mathrm{a}} & 24.82(9.82)^{\mathrm{b}} & 28.13(8.89)^{\mathrm{c}}\end{array}$

Note: EDDS = Eating Disorder Diagnostic Scale; scores on the EDDS are standardized scores. WSSQ = Weight Self-Stigma Questionnaire; enacted $=$ Fear of enacted stigma; self $=$ selfdevaluation. EDEQ DR = EDEQ dietary restraint minus instruction that restriction is for weight and shape concerns. PSWQ = shortened Penn State Worry Questionnaire. Different superscripts indicate significant difference on post-hoc tests at $\mathrm{p}<.05$. 
Table 3

Frequencies of Eating Disorders and Eating Disorder Symptoms

\begin{tabular}{|c|c|c|c|c|}
\hline & $\begin{array}{l}\text { Not Food } \\
\text { Insecure }\end{array}$ & $\begin{array}{c}\text { Household } \\
\text { Food Insecure }\end{array}$ & $\begin{array}{c}\text { Individual } \\
\text { Food Insecure }\end{array}$ & $\begin{array}{l}\text { Child Hunger } \\
\text { Food Insecure }\end{array}$ \\
\hline$\frac{\text { Clinically Significant }}{\text { Eating Disorder }^{\mathrm{a}}}$ & Available $\mathrm{n}=34$ & Available $\mathrm{n}=38$ & $\underline{\text { Available } \mathrm{n}=159}$ & $\underline{\text { Available } \mathrm{n}=200}$ \\
\hline Total Sample & $1(2.9 \%)$ & $1(2.6 \%)$ & $15(9.4 \%)$ & $34(17.0 \%)$ \\
\hline Male & $0(0.0 \%)$ & $1(16.8 \%)$ & $0(0.0 \%)$ & $8(20.0 \%)$ \\
\hline Female & $1(5.8 \%)$ & $0(0.0 \%)$ & $15(13.4 \%)$ & $26(16.4 \%)$ \\
\hline Latino/Hispanic & $0(0.0 \%)$ & $0(0.0 \%)$ & $10(10 \%)$ & $20(14.8 \%)$ \\
\hline Black/African American & $1(11.1 \%)$ & $0(0.0 \%)$ & $1(4.8 \%)$ & $6(19.4 \%)$ \\
\hline Other & $0(0.0 \%)$ & $1(16.7 \%)$ & $4(9.5 \%)$ & $7(20.0 \%)$ \\
\hline Objective Binge Eating & Available $\mathrm{n}=38$ & $\underline{\text { Available } n=42}$ & $\underline{\text { Available } n=180}$ & Available $\mathrm{n}=226$ \\
\hline Total Sample & $3(7.9 \%)$ & $1(2.4 \%)$ & $21(11.7 \%)$ & $37(16.4 \%)$ \\
\hline Male & $0(0.0 \%)$ & $1(16.7 \%)$ & $9(18.8)$ & $6(14.3 \%)$ \\
\hline Female & $3(12.0 \%)$ & $0(0.0 \%)$ & $12(9.2 \%)$ & $31(16.9 \%)$ \\
\hline Latino/Hispanic & $1(4.8 \%)$ & $0(0.0 \%)$ & $14(12.3 \%)$ & $20(13.2 \%)$ \\
\hline Black/African American & $2(18.2 \%)$ & $0(0.0 \%)$ & $2(7.4 \%)$ & $9(25.7 \%)$ \\
\hline Other & $0(0.0 \%)$ & $1(16.7 \%)$ & $5(11.9 \%)$ & $7(20.0 \%)$ \\
\hline Objective Overeating & Available $\mathrm{n}=38$ & $\underline{\text { Available } \mathrm{n}=42}$ & $\underline{\text { Available } \mathrm{n}=180}$ & Available $n=226$ \\
\hline Total Sample & $3(7.9 \%)$ & $4(8.9 \%)$ & $14(7.8 \%)$ & $27(11.9 \%)$ \\
\hline Male & $1(7.7 \%)$ & $1(16.7 \%)$ & $3(6.3 \%)$ & $5(11.9 \%)$ \\
\hline Female & $2(8.0 \%)$ & $3(8.3 \%)$ & $10(7.7 \%)$ & $22(12 \%)$ \\
\hline Latino/Hispanic & $0(0.0 \%)$ & $4(13.3 \%)$ & $8(7.0 \%)$ & $18(11.8 \%)$ \\
\hline Black/African American & $1(8.3 \%)$ & $0(0.0 \%)$ & $1(3.7 \%)$ & $3(8.6 \%)$ \\
\hline Other & $1(16.7 \%)$ & $0(0.0 \%)$ & $5(11.9 \%)$ & $6(17.1 \%)$ \\
\hline Subjective Binge Eating & Available $\mathrm{n}=38$ & Available $n=42$ & Available $\mathrm{n}=180$ & Available $\mathrm{n}=226$ \\
\hline Total Sample & $1(2.6 \%)$ & $0(0.0 \%)$ & $9(5.0 \%)$ & $21(9.3 \%)$ \\
\hline Male & $1(7.7 \%)$ & $0(0.0 \%)$ & $3(6.3 \%)$ & $4(9.5 \%)$ \\
\hline Female & $0(0.0 \%)$ & $0(0.0 \%)$ & $6(4.6 \%)$ & $17(9.3 \%)$ \\
\hline
\end{tabular}




\begin{tabular}{|c|c|c|c|c|}
\hline Latino/Hispanic & $1(4.8 \%)$ & $0(0.0 \%)$ & $8(7.0 \%)$ & $16(10.5 \%)$ \\
\hline Black/African American & $0(0.0 \%)$ & $0(0.0 \%)$ & $1(3.7 \%)$ & $1(2.9 \%)$ \\
\hline Other & $0(0.0 \%)$ & $0(0.0 \%)$ & $0(0.0 \%)$ & $4(11.4 \%)$ \\
\hline Night Eating $^{\mathrm{b}}$ & Available $\mathrm{n}=39$ & Available $\mathrm{n}=43$ & Available $\mathrm{n}=182$ & $\underline{\text { Available } n=222}$ \\
\hline Total Sample & $7(17.9 \%)$ & $6(14.0 \%)$ & $35(19.2 \%)$ & $85(38.3 \%)$ \\
\hline Male & $3(21.4 \%)$ & $1(12.5 \%)$ & $13(26.5 \%)$ & $16(39.0 \%)$ \\
\hline Female & $4(16.0 \%)$ & $5(13.5 \%)$ & $22(16.7 \%)$ & $68(37.8 \%)$ \\
\hline Latino/Hispanic & $1(4.8 \%)$ & $3(10 \%)$ & $26(23.2 \%)$ & $54(35.8 \%)$ \\
\hline Black/African American & $4(33.3 \%)$ & $2(25 \%)$ & $2(7.1 \%)$ & $15(44.1 \%)$ \\
\hline Other & $1(16.7 \%)$ & $1(16.7 \%)$ & $7(16.7 \%)$ & $15(42.8 \%)$ \\
\hline$\underline{\text { Vomiting }}$ & $\underline{\text { Available } \mathrm{n}=39}$ & $\underline{\text { Available } \mathrm{n}=43}$ & Available $\mathrm{n}=182$ & Available $\mathrm{n}=221$ \\
\hline Total Sample & $1(2.6 \%)$ & $3(7.0 \%)$ & $23(12.6 \%)$ & $45(20.4 \%)$ \\
\hline Male & $1(7.1 \%)$ & $1(16.7 \%)$ & $10(20.8 \%)$ & $12(29.3 \%)$ \\
\hline Female & $0(0.0 \%)$ & $2(5.4 \%)$ & $13(9.8 \%)$ & $33(18.4 \%)$ \\
\hline Latino/Hispanic & $0(0.0 \%)$ & $1(3.3 \%)$ & $18(16.1 \%)$ & $23(15.3 \%)$ \\
\hline Black/African American & $1(8.3 \%)$ & $1(12.5 \%)$ & $1(3.6 \%)$ & $13(38.2 \%)$ \\
\hline Other & $0(0.0 \%)$ & $1(20.0 \%)$ & $4(9.5 \%)$ & $9(27.3 \%)$ \\
\hline$\underline{\text { Laxatives/Water Pills }}$ & Available $\mathrm{n}=38$ & Available $\mathrm{n}=43$ & $\underline{\text { Available } \mathrm{n}=178}$ & $\underline{\text { Available } \mathrm{n}=219}$ \\
\hline Total Sample & $1(2.6 \%)$ & $5(11.6 \%)$ & $34(19.1 \%)$ & $50(22.8 \%)$ \\
\hline Male & $1(7.1 \%)$ & $0(0.0 \%)$ & $12(26.1 \%)$ & $10(24.4 \%)$ \\
\hline Female & $0(0.0 \%)$ & $5(13.5 \%)$ & $22(16.9 \%)$ & $40(22.6 \%)$ \\
\hline Latino/Hispanic & $0(0.0 \%)$ & $3(10 \%)$ & $26(23.9 \%)$ & $30(19.9 \%)$ \\
\hline Black/African American & $1(8.3 \%)$ & $1(12.5 \%)$ & $1(3.6 \%)$ & $11(34.4 \%)$ \\
\hline Other & $0(0.0 \%)$ & $1(20 \%)$ & $7(17.1 \%)$ & $9(28.1 \%)$ \\
\hline
\end{tabular}

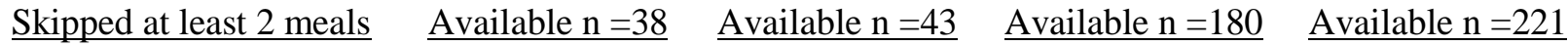
in a row

$\begin{array}{lcccc}\text { Total Sample } & \mathbf{5 ( 1 3 . 2 \% )} & \mathbf{1 0}(\mathbf{2 3 . 3 \%}) & \mathbf{6 6}(\mathbf{3 6 . 7 \%}) & \mathbf{1 1 1}(\mathbf{5 0 . 2 \%}) \\ \text { Male } & 4(28.6 \%) & 1(16.7 \%) & 21(44.7 \%) & 21(51.2 \%) \\ \text { Female } & 1(4.2 \%) & 9(24.3 \%) & 45(34.4 \%) & 90(50.3 \%) \\ \text { Latino/Hispanic } & 0(0.0 \%) & 7(23.3 \%) & 45(40.5 \%) & 66(44.0 \%)\end{array}$




\begin{tabular}{|c|c|c|c|c|}
\hline Black/African American & $4(36.4 \%)$ & $1(12.5 \%)$ & $6(21.4 \%)$ & $21(61.8 \%)$ \\
\hline Other & $1(16.7 \%)$ & $2(40 \%)$ & $15(36.6 \%)$ & $22(66.7 \%)$ \\
\hline $\begin{array}{l}\text { Exercised harder than } \\
\text { usual because ate too } \\
\text { much }\end{array}$ & $\underline{\text { Available } \mathrm{n}=39}$ & $\underline{\text { Available } n=43}$ & $\underline{\text { Available } n=182}$ & $\underline{\text { Available } \mathrm{n}=21}$ \\
\hline Total Sample & $6(15.4 \%)$ & $10(23.3 \%)$ & $46(25.2 \%)$ & $76(34.7 \%)$ \\
\hline Male & $3(21.4 \%)$ & $3(50 \%)$ & $12(25.5 \%)$ & $17(41.5 \%)$ \\
\hline Female & $3(12 \%)$ & $7(18.9 \%)$ & $33(24.8 \%)$ & $58(32.8 \%)$ \\
\hline Latino/Hispanic & $2(9.5 \%)$ & $8(26.7 \%)$ & $31(27.4 \%)$ & $50(33.3 \%)$ \\
\hline Black/African American & $3(27.3 \%)$ & $1(12.5 \%)$ & $4(14.3 \%)$ & $14(42.4 \%)$ \\
\hline Other & $0(0.0 \%)$ & $1(20 \%)$ & $11(26.8 \%)$ & $12(37.5 \%)$ \\
\hline $\begin{array}{l}\text { Weight/Shape } \\
\text { Concerns } \geq 4\end{array}$ & Available $\mathrm{n}=37$ & Available $\mathrm{n}=45$ & $\underline{\text { Available } \mathrm{n}=187}$ & Available $\mathrm{n}=22$ \\
\hline Total Sample & $5(13.5 \%)$ & $8(17.8 \%)$ & $54(28.9 \%)$ & $71(31.6 \%)$ \\
\hline Male & $0(0.0 \%)$ & $0(0.0 \%)$ & $7(14.3 \%)$ & $8(19.0 \%)$ \\
\hline Female & $5(20.8 \%)$ & $8(21.6 \%)$ & $47(34.6 \%)$ & $63(34.6 \%)$ \\
\hline Latino/Hispanic & $2(10.5 \%)$ & $4(12.9 \%)$ & $33(28.2 \%)$ & $49(32.5 \%)$ \\
\hline Black/African American & $2(18.2 \%)$ & $2(25.0 \%)$ & $4(14.3 \%)$ & $13(37.1 \%)$ \\
\hline Other & $1(16.7 \%)$ & $2(33.3 \%)$ & $17(40.5 \%)$ & $7(20.0 \%)$ \\
\hline
\end{tabular}

${ }^{a}$ Scoring above 16.5 standardized cutoff on EDDS.

${ }^{b}$ Night eating after waking from sleep a large amount of food with distress

Note: Available n's = available responses within each food insecurity category for total sample; valid percentages calculated based on total number of responses on main dependent variable within each food insecurity category for total sample; gender and ethnicity sample percentages calculated as valid percentages of responses within food insecurity group and gender or ethnicity. 
Acknowledgments: The authors would like to thank the San Antonio Food Bank and affiliated Food Pantries for their assistance in this research. We also thank the HEB Grocery Company, McNairs Scholars Program, and Murchison Summer Undergraduate Research Fellowship Program for financial support. 